\title{
A SURVEY OF IRRIGATION PRACTICE AMONG DENTAL PRACTITIONERS IN HIMACHAL PRADESH
}

\author{
Damanpreet $^{1}$, Saurav Miglani ${ }^{2}$, Babita Karda ${ }^{3}$, Palvi Sarangal ${ }^{4}$ \\ ${ }^{1}$ Sr. Lecturer, Department of Conservative Dentistry \& Endodontics, Bhojia Dental College \& Hospital, Bhud, Baddi, Himachal Pradesh. \\ ${ }^{2}$ Sr. Lecturer, Department of Conservative Dentistry \& Endodontics, Desh Bhagat Dental College \& Hospital, Mukstar, Punjab. \\ ${ }^{3}$ Sr. Lecturer, Department of Pediatric \& Preventive Dentistry, Desh Bhagat Dental College \& Hospital, Mukstar, Punjab. \\ ${ }^{4}$ Sr. Lecturer, Department of Periodontology \& Oral Implantology, Bhojia Dental College \& Hospital, Bhud, Baddi, Himachal Pradesh.
}

Corresponding Author: Damanpreet Mobile: $+91-7696300005$ E-mail: daman_1510@yahoo.com

Received: $16^{\text {th }}$ May 2014 Accepted: 20th Aug 2014 Online: $20^{\text {th }}$ Sept 2014

Aim: The purpose of this study was to determine current trends in irrigation practice among the practicing dentists in Himachal Pradesh. Methodology: A self prepared questionnaire comprising of 15 questions was emailed to 1970 members of the State Dental Council of Himachal Pradesh. The information gathered was the individual irrigant selection, irrigant concentration, smear layer removal, and use of adjuncts to irrigation. Results: A total of 544 replies were evaluated thus making the response rate of $27.6 \%$ for the study. Our data indicated that $38 \%$ of respondents primarily use sodium hypochlorite, with $61 \%$ of them using it at a concentration $>5.0 \%$. Only $21 \%$ of respondents aimed to remove the smear layer during endodontic treatment with only $7 \%$ using an adjunct to irrigation. Antibacterial activity was rated as the most important reason while selecting an irrigant. Conclusion: In spite of the crucial nature of the irrigation step in the endodontic therapy, the results of the study were not very satisfying especially when it comes to the use of adjuncts or newer irrigating systems. Thus there is need to regularly update and gauge the practices adopted by dental practitioners in the state.

Key Words: Dental Practitioners, Irrigant, Sodium Hypochlorite.

\section{INTRODUCTION}

The complex anatomy of root canal systems demand the use of various adjuncts during cleaning and shaping before the final obturation. The root canal is shaped with hand and rotary instruments under constant irrigation to remove the inflamed and necrotic tissue, microbes/biofilms, and other debris from the root canal space. The main goal of instrumentation is to facilitate effective irrigation, disinfection, and filling. However, there is no single irrigating solution that alone sufficiently covers all of the functions required from an irrigant. ${ }^{1}$ Some irrigating solutions dissolve either organic or inorganic tissue in the root canal. In addition, several irrigating solutions have antimicrobial activity and actively kill bacteria and yeasts when introduced in direct contact with the microorganisms. At the same time several irrigating solutions also have cytotoxic potential, and they may cause severe pain if they gain access into the periapical tissues. $^{2}$

The most widely used endodontic irrigant is $0.5 \%$ to $6.0 \%$ sodium hypochlorite $(\mathrm{NaOCl})$, because of its bactericidal activity and ability to dissolve vital and necrotic organic tissue. ${ }^{3,4}$ However, $\mathrm{NaOCl}$ solutions exert no effects on inorganic components of smear layer. Chelant and acid solutions have been recommended for removing the smear layer from instrumented root canals, including ethylene diaminetetraacetic acid (EDTA), citric acid, and phosphoric acid. $^{5,6}$

Controversy exists regarding whether it is advantageous to remove the smear layer that is formed during root canal instrumentation. Current methods to 
remove the smear layer might involve the use of a chelating agent during irrigation or as a final rinse in combination with other irrigants. Ethylene diaminetetraacetic acid (EDTA) is effective for removing the inorganic component of the smear layer. ${ }^{7}$ In an effort to improve the delivery and effectiveness of irrigants, different adjuncts have been developed. Both sonic and ultrasonic agitation of the irrigant has been studied for their ability to improve canal cleanliness. Systems such as EndoVac (Discus Dental, Culver City, CA) use negative pressure to safely bring irrigants into contact with all surfaces of the root canal. ${ }^{8}$

Although many different irrigants and treatment protocols have been studied, little research has been conducted to determine the widespread practice or acceptance of such methods and materials among General Dental Practitioners (GDPs). So the present study was conducted to ascertain the current trends in irrigation among active dental practitioners in Himachal Pradesh.

\section{MATERIAL \& METHODS}

A self-prepared questionnaire was electronically mailed to a total of 1970 dentists registered with State Dental Council, Himachal Pradesh. The questionnaire was made up of 15 questions with multiple-choice answers covering all the aspects of irrigation protocol in endodontics.

The questions were so framed to cover all the information regarding irrigation, ranging from irrigant selection, irrigant concentration, smear layer removal, to use of adjuncts to irrigation. Questions consisted of numeric rankings, multiple choices, and multiple selections with options for write-in answers where appropriate. The survey was closed after 6 weeks.

The data were compiled by a single assessor and analyzed using the statistical software SPSS. Blank or multiple answers were all treated as missing values; only single unequivocal replies were included in calculating frequencies and percentages.

\section{RESULTS}

Out of 1970 questionnaires mailed, 558 replies were received of which 14 were found unusable leaving 544 useable responses, thus giving a response rate of $27.6 \%$ for the study. The results indicated that $>38 \%$ of respondents were using sodium hypochlorite as their primary irrigant. (Figure 1)

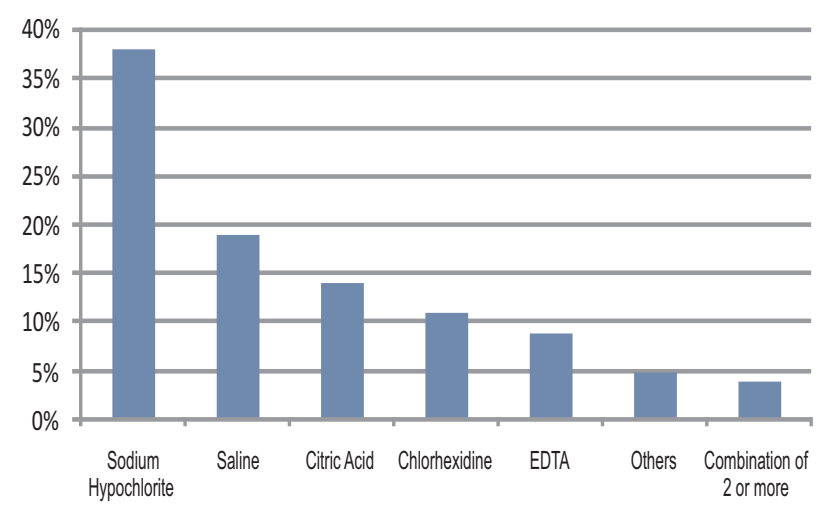

Figure 1: Percentage of respondents who utilize each irrigant as their primary or main irrigant during Endodontic treatment

When asked to rank the reasons for their primary irrigant selection, antibacterial capability was most important, followed in order by biocompatibility, tissue dissolution, expense and substantivity. Most of the practitioners using sodium hypochlorite were found preferring full-strength sodium hypochlorite $(\mathrm{NaOCl}$ concentration $>5.0 \%$ ) with $32 \%$ of them using it in concentration range of $1.5-5 \%$ and only $7 \%$ opting for lower concentration $(<1.5 \%)$. Only $21 \%$ of respondents aim to remove the smear layer during endodontic treatment. Most practitioners (74\%) reported to not alter their irrigant selection on the basis of pulpal or periapical diagnosis with only $9 \%$ of them preferring metronidazole or other irrigants for the teeth with necrotic pulps. An extremely less percentage of respondents (7\%) use an adjunct to irrigation, with 5\% using ultrasonic activation and $2 \%$ using sonic activation. None of the practitioners were found using negative pressure irrigation with systems such as EndoVac.

\section{DISCUSSION}

This project sought to collect data from general dental practitioners in Himachal Pradesh. The E mail addresses of the dentists were taken from the State Dental Council and the questionnaires were mailed electronically. It was stated at the beginning of the 
questionnaire that only the dentists who are in practice should go ahead to fill the survey form. Such surveys provide a simple means of data collection, but they are often weakened by poor rates of return. The response rate $(27.6 \%)$ was poor but a second mail shot was impossible because the survey was anonymous. A similar survey held among the members of the American Association of Endodontists also had a low response rate of $28.5 \%$.

In this study, it was found that the majority of respondents (38\%) use sodium hypochlorite as their primary irrigant, with most of them (61\%) using a concentration of $5 \%$ or greater. The probable reason for the popularity of $\mathrm{NaOCl}$ may be attributed to its high tissue dissolving capacity and anti bacterial property as latter was found to be the highest ranked reason for the irrigant selection in the study. The results were however not comparable to a survey conducted in Australia which reported that $94 \%$ of endodontists used Sodium Hypochlorite, with $80 \%$ of those surveyed using a $1 \% \mathrm{NaOCl}$ solution. ${ }^{10}$ At the same time, the use of chief irrigants with good substantivity like chlorhexidine was found to be low among the respondents. The earlier studies by Torabinejad recommend the use of chlorhexidine as root canal irrigant especially in the cases of retreatment $\&$ failures which have increased in the past. ${ }^{11,12}$

A very less percentage of $21 \%$ respondents in the study aimed to remove smear layer thus showing that majority of dental practitioners in the state were not routinely using irrigants like EDTA and citric acid which are effective in smear layer removal. (Figure 1). However the above finding is in contrast to other studies in which more than $50 \%$ dentists were routinely removing smear layer before obturation., ${ }^{9,13}$

A majority (84\%) of respondents in our study stated that their choice of irrigant does not change on the basis of pulpal and periapical diagnosis. A very few (11\%) were found preferring irrigants like metronidazole for teeth with necrotic pulps. This finding might be a significant reason behind the failure of root canal treatment experienced by GDPs in their respective practices. These answers should be interpreted with caution because the questions were not open-ended and did not allow protocols with multiple irrigants to be considered.'

When asked about adjuncts used for irrigation, participants were given choices including ultrasonic activation, sonic activation, and negative pressure. Participants also had the option to write in an adjunct. In our study, a very disappointing percentage of only $7 \%$ respondents were found using any kind of adjunct to irrigation with no one using negative pressure irrigation systems. These results indicate a very high need to introduce such systems at reasonably lower cost to make the same popular among practitioners.

The results on all the aspects of irrigant usage among the practitioners in the present study indicate a need to update them regarding the intelligent use of irrigating solutions for optimum results in endodontic treatment.

\section{CONCLUSION}

The use of irrigants undoubtedly constitutes a very crucial step for the success of root canal treatment. Smear layer removal, eradication of pathogenic microorganisms and complete elimination of debris is essential to achieve a hermetic seal of the obturating material. To accomplish all the above-mentioned factors, a very intelligent use of irrigant, either alone or in combination is required. The results of the present study however showed that there is a high need to upgrade and at the same time keep a regular check on the methods adopted by the Dental Practitioners in the state of Himachal Pradesh. Also, newer irrigation techniques and armamentarium should be made available at lower costs to encourage their usage among the practicing dentists. Though further studies with high response rate are recommended for better delineation of practices of dentists in the state. 


\section{REFERENCES}

1. Haapasalo M, Shen Y, Qian W, Gao Y. Irrigation in Endodontics. Dent Clin NAm 2010;54:291-312.

2. Hulsmann M, Hahn W. Complications during root canal irrigation: literature review and case reports. Int Endod J 2000;33:186-93.

3. Carson KR, Goodell GG, McClanahan SB. Comparison of the antimicrobial activity of six irrigants on primary endodontic pathogens. J Endod. 2005;31:471-473.

4. Clegg MS, Vertucci FJ, Walker C, Belanger M, Britto LR. The effect of exposure to irrigant solutions on apical dentin biofilms in vitro. J Endod. 2006;32:434-437.

5. Garberoglio R, Becce C. Smear layer removal by root canal irrigants. A comparative scanning electron microscopic study. Oral Surgery, Oral Medicine, Oral Pathology. 1994;78(3):359-367.

6. Ayad MF. Effects of rotary instrumentation and different etchants on removal of smear layer on human dentin. Journal of Prosthetic Dentistry 2001;85(1):67-72.

7. Torabinejad M, Khademi AA, Babagoli J, Cho Y, Johnson WB, Bozhilov K et al. A new solution for removal of the smear layer. J Endod 2003;29:170-5.
8. Gu L, Kim JR, Ling J, Choi KK, Pashley D, Tay F. Review of contemporary irrigant agitation techniques and devices. $\mathrm{J}$ Endod 2009;35:791-804.

9. Dutner J, Mines P, Anderson A. Irrigation Trends among American Association of Endodontists Members: A Webbased Survey. J Endod. 2012;38(1):37-40.

10. Clarkson RM, Podlich HM, Savage NW, Moule AJ. A survey of sodium hypochlorite use by general dental practitioners and endodontists in Australia. Aust Dent J 2003;48:20-6.

11. Ohara P, Torabinejad M, Kettering JD. Antibacterial effect of various endodontuic irrigants on selected anaerobic bacterias. Endod dent Traumatol 1993;9:95-100

12. Erecan E, Ozekinci T, Atakul F, Gul K. Antibacterial activity of $2 \%$ chlorhexidine gluconate and $5.25 \%$ sodium hypochlorite in infected root canals in vivo study. J Endod. 2004;30:84-87.

13. Moss HD, Allemang JD, Johnson JD. Philosophies and practices regarding the management of the endodontic smear layer: results from two surveys. J Endod 2001;27:537-9. 